\title{
A PROPRIEDADE COMO DIREITO (NÃO) FUNDAMENTAL NA CONSTITUIÇÃO BRASILEIRA
}

\author{
PROPERTY RIGHTS AS (NO) FUNDAMENTAL TO THE BRAZILIAN \\ CONSTITUTION
}

\author{
Álvaro Borges de Oliveira ${ }^{1}$ \\ Daniele Cristina Rossetto ${ }^{2}$
}

\begin{abstract}
RESUMO - A propriedade se caracteriza pela necessidade do homem de possuir objetos essenciais para sua existência. Contudo, para se verificar o significado do termo é necessário investigar a etimologia da palavra, pois deste sentido decorre o sentido jurídico de que propriedade é o direito de dispor de alguma coisa de modo pleno, e de outro uma obrigação. Verifica-se, desta forma, a idéia de poder implícita na propriedade, entendido como capacidade de controlar e impor a própria vontade. Por essas e outras razões, a propriedade sempre foi foco de conflitos sociais, medindo a riqueza e o poder dos indivíduos e se constituindo na base do direito privado. Determinar a origem da propriedade sempre foi um desafio para filósofos e teóricos, que se dividiam, principalmente, em dois grupos: os que afirmavam ser a propriedade um direito natural e independente do surgimento do Estado e os que sustentavam que o direito de propriedade nasce somente como conseqüência do Estado. Assim, partindo deste ponto discute-se neste artigo se a propriedade é ou não direito fundamental.
\end{abstract}

PALAVRAS-CHAVE - Constituição. Direito Fundamental. Propriedade.

ABSTRACT - The needs of men and the underlying ideological influences of each people were, throughout the history of mankind, being recognized from political struggles that proclaimed norms and laws to regulate life in society. In this context one can infer the emergence of the state, which is meant to be tied to the origin of man and property. The characteristics of the evolution of the State or political society are peculiar to each instance of this, and underlined by various philosophers and researchers who have clung to this study. Although there are different theories and theorists who seek to define when and how was the beginning of the State or political society, this study will be based on the analysis of a State conceived under the optics of contractualism, then look for the institute of Property especially as there was its recognition and treatment in order to relate it to

\footnotetext{
${ }^{1}$ Professor titular dos Cursos de Doutorado, Mestrado e Graduação em Ciência Jurídica na Universidade do Vale do Itajaí. Graduado em Direito pela Universidade do Vale do Itajaí (2002), graduação em Ciências da Computação pela Universidade Federal de Santa Catarina (1984), mestrado em Engenharia de Produção pela Universidade Federal de Santa Catarina (1992), mestrado em Ciência Jurídica pela Universidade do Vale do Itajaí (2005) e doutorado em Engenharia de Produção pela Universidade Federal de Santa Catarina (2000). E-mail: alvaro@univali.br

${ }^{2}$ Mestre em Ciência Jurídica - Universidade do Vale do Itajaí. E-mail: staffen_sc@univali.br.
} 
contemporary times, in other words, the target of analysis will be focused on the property from the Modern State from the perspective of contractarian, to the advent of the Constitutional State nowadays . This theoretical distinction is justified on the grounds that the private character of property or individualistic appeared only with the advent of the Modern State, behold, there came a man having rights and obligations, seeing therefore in antiquity, a property with its own characteristics, however, different from the current conception of property, as it will be exposed. So we share the idea that property in its current direction, should be studied from the French Revolution, which had a decisive collaboration to meet the inherent powers of the Property, setting the power of the owner, who later suffered socialization.

KEYWORDS - Constitution. Fundamental rights. Property.

\section{INTRODUÇÃO}

A propriedade se caracteriza pela necessidade do homem de possuir objetos essenciais para sua existência. Contudo, para se verificar o significado do termo é necessário investigar a etimologia da palavra.

Analisando do termo Propriedade Norberto Bobbio (1994) afirma que "(...) deriva do adjetivo latino proprius e significa que é de um indivíduo específico ou de um objeto específico, sendo apenas seu".

Do sentido etimológico decorre o sentido jurídico de que propriedade é o direito de dispor de alguma coisa de modo pleno, sem limites. Verifica-se, desta forma, a idéia de poder implícita na propriedade, entendido como capacidade de controlar e impor a própria vontade.

Por essas e outras razões, a propriedade sempre foi foco de conflitos sociais, medindo a riqueza e o poder dos indivíduos e se constituindo na base do direito privado.

A primeira propriedade, pelo que se depreende do estudo feito, foi coletiva, onde todos usavam a terra para seu sustento e sobrevivência. De acordo com Loureiro (2003), mais tarde a propriedade era familiar, e a propriedade privada, aparece com o surgimento da agricultura e da pecuária, nessa fase estão os gregos da época heróica, as tribos itálicas anteriores à fundação de Roma e os nórdicos.

Determinar a origem da propriedade sempre foi um desafio para filósofos e teóricos, que se dividiam, principalmente, em dois grupos: os que afirmavam ser a 
propriedade um direito natural e independente do surgimento do Estado ${ }^{3}$ e os que sustentavam que o direito de propriedade nasce somente como conseqüência do Estado ${ }^{4}$.

\section{ORIGEM E EVOLUÇÃO DA PROPRIEDADE}

Além dessa dificuldade de se determinar a origem da propriedade, 0 processo histórico de evolução da propriedade teve contornos sociais e econômicos de acordo com o momento histórico vivido.

$\mathrm{Na}$ Antiguidade a propriedade tinha caráter divino, ela integrava a religião doméstica, era vinculada aos bens da família (gens) e usada para adorar os deuses domésticos, pessoas da família que já tinham falecido.

Nesse sentido observasse o elo entre as três instituições - família, propriedade e religião na antiguidade, a família está ligada ao altar e este a terra. Fixada a família no solo, instalava-se ali o lar e os seus respectivos deuses, conferindo um caráter sagrado à posse e à propriedade (FUSTEL DE COULANGES, 1966).

No período pré-clássico, das origens de Roma, entre 754 a.C e 126 a.C, a única espécie reconhecida de propriedade era a quirinária - aquela decorrente da constituição da cidade de Roma, típica dos patrícios - bem como a propriedade sobre as terras conquistadas.

Num primeiro momento, o proprietário exercia poder absoluto e total sobre o bem, podendo empregar qualquer ação ou até mesmo não dar a ele uma destinação, sem sofrer conseqüências. Pois o pater do grupo familiar exercia sua autoridade sobre a terra sem qualquer interferência do Estado.

Para Costa (2003), a proteção conferida pelo Estado à propriedade quirinária era tanta que ela gozava de imunidade fiscal, posto que a

\footnotetext{
${ }^{3}$ Dentre eles: John Locke, para quem o direito de propriedade é a base da liberdade humana "porque todo homem tem uma propriedade que é sua própria pessoa". O governo existe para proteger esse direito.

${ }^{4}$ Dentre eles: Hobbes e Rousseau.
} 
cobrança tributária representaria diminuição à onipotência do pater familiae exercendo este, então, um poder político e jurisdicional sobre o seu núcleo familiar.

Em Roma, diferentemente do que sucedeu entre outros povos como o grego, a propriedade individual constitui-se sob um aspecto muito forte, e o gênio jurídico da raça mais energicamente o reforçou. Os juristas deram ao conceito de propriedade o sentido mais rigoroso do mundo, porquanto foi tida como um direito absoluto, armada dos meios de defesa mais eficientes (SERPA LOPES, 1960).

$\mathrm{Na}$ fase do direito clássico, de 126 a.C à 305 d.C, os romanos reconheceram mais três espécies de propriedade: a bonitária ou pretoriana, a provincial e a peregrina.

A propriedade bonitária ou pretoriana era a proteção conferida pelo pretor ao adquirente de propriedade, em que a aquisição não obedecesse aos requisitos do jus civile, contudo, o comprador só adquiria a propriedade com o decurso de tempo para o usucapião.

No entanto, a propriedade provincial constituía no uso de terras do Estado romano por parte de particulares, estes em contrapartida pagavam uma contribuição ao Estado.

Quanto à propriedade peregrina, era uma espécie de propriedade de fato, pois os peregrinos eram impossibilitados de ter propriedade quirinária dos bens.

Já na Época Pós-Clássica, de 305 d.C até 565 d.C, houve uma unificação das espécies de propriedade, resultando uma categoria única de propriedade privada, que era transferida pela traditio, estava submetida ao pagamento de impostos e sujeitava-se a inúmeras limitações de ordem pública.

Justiniano unificou a propriedade romana. Desapareceram, antes dele, a propriedade itálica e a provincial. A propriedade pretoriana perdera a sua razão de ser, em virtude da extinção de todas as suas aplicações e da diferença entre res mancipi e nec mancipi. Agora, há somente um dominium ou proprietas, e que recai sobre qualquer coisa, acessível a todo cidadão (CHAMOUN, 1957). 
Segundo Costa (2003), a Idade média contrariou o modelo exclusivista da propriedade romana, instituindo um sucessório enfitêutico ao qual correspondia uma superposição de titularidades dominiais, fundamentadas na hierarquia dos feudos que, a seu turno, identificava-se com a hierarquia das pessoas.

Durante o feudalismo o regime dos bens era determinada pelo estamento do grupo feudal ao qual pertencia a pessoa que nele figurava como titular do direito.

Para Costa (2003), existia um vínculo jurídico entre os possuidores da terra e os que nela cultivavam, sendo os primeiros apenas donos do bem, sem que exercessem nele qualquer atividade agrícola; quanto aos segundos, por sua vez, era o contrário. Mais tarde concedeu-se aos que trabalhavam na terra, o direito de possuí-la com algum ônus obrigacional perpétuo, logo não tinham a propriedade que era mantida no domínio eminente das famílias nobres, mas um direito real sobre coisa alheia.

O conceito de propriedade abandona o caráter unitário para consagrar uma superposição de direitos sobre o mesmo bem, dando a cada um deles a mesma natureza, mas uma densidade diferente (WALD, 1991).

Esse domínio paralelo do senhor feudal, na verdade, era resultante de uma confusão existente na época entre direitos civis e direitos políticos, era um tipo de soberania que o senhor feudal exercia sobre a propriedade.

De acordo com Costa (2003), a produção de excedentes fez com que os feudos buscassem comercializar seus produtos, começaram a organizar feiras e em torno dessas mais tarde vão se estruturas os burgos (cidades).

Com a crise do feudalismo, ocasionada pelas epidemias, exploração agrícola predatória e extensiva, lutas da burguesia contra nobreza, ocorreram profundas transformações nas estruturas feudais, começou-se a quebrar a rigidez social de ordens ou estamentos, e a burguesia se aproximou do poder. 
No campo intelectual, surge o iluminismo, caracterizado pela importância da razão para felicidade do homem, atacavam a injustiça e defendiam a liberdade individual, a livre posse dos bens, tolerância das divergências e garantia dos direitos individuais (COSTA, 2002).

Nesse período a Revolução Comercial e 0 mercantilismo impulsionaram a derrocada do modelo feudal ora estabelecido, sobretudo na organização social e na propriedade, surgindo a idéia de propriedade como utilidade econômica, e passa a ser figura central do Direito Privado a partir do século XIX.

\section{A PROPRIEDADE COMO GARANTIA INDIVDUAL PARA OS JUSNATURALISTAS: LOCKE, HOBBES E ROUSSEAU}

Os representantes do jusnaturalismo - teoria dos direitos naturais, explicam o surgimento do Estado através da elaboração de um grande pacto ou contrato social entre os homens que antes viviam em estado de natureza, no qual abririam mão de suas liberdades naturais para que seus direitos naturais fossem garantidos pelo Estado.

A propriedade para Locke era entendida em dois sentidos, um bastante amplo no qual inseria o direito de vida, de liberdade e de propriedade, outro restrito, e acreditava que a propriedade era um direito natural do indivíduo, fundamentada em seu trabalho.

[...] apesar de natureza se oferecer a nós em comum, por ser o homem senhor de si próprio e dono de si mesmo, das suas ações e do trabalho que executa, tem ainda em si mesmo os fundamentos da propriedade; e tudo aquilo que se aplica ao próprio sustento ou conforto, quando as invenções e as artes aperfeiçoa as conveniências da vida, é totalmente propriedade sua, não pertencendo a mais ninguém (HOBBES, 1983).

No discurso de Rousseau a finalidade última do Estado seria servir aos interesses individuais daqueles que o compõe, devendo ser neutro. 
Rousseau afirmou que o direito de propriedade é o mais sagrado de todos os direitos dos cidadãos e mais importante que a própria liberdade, pois todos os direitos civis fundam-se na propriedade, assim se abolir este último nenhum outro pode subsistir.

A idéia central do pensamento de Thomas Hobbes está situada na sua visão acerca da natureza humana, para ele os homens em estado de natureza competem uns com os outros pelo poder, riquezas e propriedade. Hobbes sustentava que para o direito de propriedade seja assegurado, imprescindível se faz a tutela estatal, pois os homens em seu estado de natureza tinham a posse coletiva sobre todos os bens (COSTA, 2003).

A partir desta fundamentação, a propriedade tornou-se garantia fundamental da liberdade do cidadão contra as imposições do Estado, como direito natural e imprescritível do homem a propriedade era instituto exclusivamente do Direito privado, estranho à organização do Estado.

Quando o homem transformava a matéria bruta através do seu trabalho, tornava-se o seu proprietário. Mas essa propriedade fundada no trabalho era limitada, pois as coisas úteis ao homem eram de curta duração. A passagem da propriedade limitada (propriedade meio) para a propriedade ilimitada (propriedade fim), deu-se com o surgimento do dinheiro (para possibilitar o comércio) e fez surgir a distribuição desigual.

Segundo Franzoni (2004), a propriedade tinha um fim em si mesma, servindo de capital para gerar mais capital, como conseqüência de um período marcado pelo advento da Revolução Industrial, quando o ciclo manufatureiro evoluía para o ciclo do maquinismo. O capitalismo ascendia vertiginosamente.

A evolução sócio-econômica do último século, com a concentração capitalista, tornou cada vez mais precária a situação dos que não possuem propriedade. E, contra os excessos no uso do direito de propriedade, foi preciso reconhecer que a subsistência individual merecia uma proteção 
constitucional semelhante à dispensada tradicionalmente à propriedade.

\section{A PROPRIEDADE CONDICIONADA AO INTERESSE SOCIAL}

Através do Socialismo e do Catolicismo Social inseriu-se na reflexão jurídica a concepção de propriedade privada individual condicionada ao interesse social.

Da constatação de que a igualdade dos homens não existe, inicia-se uma releitura do conceito de liberdade pelo Estado Social: se existir liberdade nas relações entre os homens desiguais isso gerará injustiças, é razoável, portanto intervenção Estatal para equilibrar a relação, e a forma de intervenção é o Direito.

Portanto, a propriedade não pode mais ser considerada absoluta frente às novas concepções da sociedade, está cada vez mais submetida à função social que impõe uma série de limitações ao seu exercício.

A Constituição além de limitar a incursão de terceiros sobre a propriedade, determina o seu conteúdo de forma a orientá-la para o bemestar social.

Com efeito, o bem-estar social inicia-se com as liberdades positivas, o que se costuma denominar processo de "publicização do privado". Este tem como marca a intervenção do Estado, dos poderes públicos na regulação da atividade econômica, onde o interesse geral, político, deve se sobrepor ao interesse privado, econômico (CANOTILHO, 1995).

Desse contexto decorre a previsão constitucional de relações antes reguladas apenas pelo Direito Civil, os interesses individuais são também disciplinados pelas normas públicas. Os institutos continuam sendo de Direito Privado, mas impregnados de caráter público, tornando os portadores de uma função social. Nascendo o que se convencionou chamar de direitos de segunda geração, os direitos sociais. 
O problema hoje, com o fenômeno da globalização, é saber como se regularão os deveres e obrigações num centro político estadual e se este ainda permanecerá.

As Constituições, embora continuem a ser pontos de legitimação, legitimidade e consenso autocentradas numa comunidade estadualmente organizada, devem abrir-se progressivamente a uma rede cooperativa de metanormas ('estratégias internacionais', 'pressões concentradas') e de normas oriundas de outros 'centros' transnacionais e infranacionais (regionais e locais) ou de ordens institucionais intermédias ('associações internacionais', 'programas internacionais') (SILVA, 1998).

A Constituição não pode mais ser analisada a partir de critérios puramente lógico-formais, deve-se entendê-la como forma de realização de conteúdos axiológicos, políticos, econômicos ou culturais, considerando a realidade e os elementos formadores do Direito.

Um novo paradigma para a sociedade é estabelecido pela Carta Magna de 1988, através do reconhecidos de conflitos sociais latentes, se procura uma composição dos interesses envolvidos, a exemplo da previsão do princípio da propriedade privada e o princípio da função social da propriedade previstos no arts. 170, inciso I e II e 5o inciso XXII e XXIII.

Muitas vezes essa composição de interesses, abstratamente falando, pode apresentar uma colisão entre direitos, que ocorre quando o exercício de um direito fundamental por parte do seu titular colide com o exercício de um direito fundamental de outro.

Portanto, na resolução das tensões que se produzem dentro do sistema normativo, relevante se faz a distinção entre regras e princípios tendo em vista a necessidade de utilização de técnicas diferenciadas para cada caso.

Quando dois princípios entram em colisão, um deve ceder em relação ao outro, sem que se lhe declare a invalidade ou se the insira cláusula de exceção, como acontece no conflito entre regras.

A tensão entre princípios se resolve mediante uma ponderação de 
interesses opostos, determinando qual destes interesses, abstratamente, possui maior peso no caso concreto. $\mathrm{Na}$ análise de qual direito deve prevalecer deve-se usar o princípio da proporcionalidade, conservando-se o de maior relevância jurídica.

Neste diapasão, princípio fundamental da função social da propriedade constitui 0 alicerce constitucional do regime jurídicoconstitucional da propriedade, estando todos os demais princípios e regras constitucionais a ele submetidos, inclusive o princípio da propriedade privada estabelecido no art. 170, II, da Lei Maior.

\section{A PROPRIEDADE COMO DIREITO (NÃO) FUNDAMENTAL}

A Constituição assegura o direito de propriedade e estabelece seu regime fundamental, cabendo ao Direito Civil exclusivamente disciplinar as relações civis a ela inerentes. Deste modo, as disposições do Código Civil só valem no âmbito das relações civis, mesmo assim com as delimitações e condicionamentos que das normas constitucionais defluem para a estrutura do direito de propriedade em geral.

O direito à propriedade revela-se como um direito constitucional com a mesma relevância do direito à vida, pois ambos estão disciplinados no mesmo Título da Carta, qual seja o dos direitos e garantias fundamentais. Não há óbice para o exercício do Direito à Vida, porém não podemos dizer o mesmo do Direito à propriedade, cujo exercício está condicionado à função social, ou seja a ordem jurídica confere ao "proprietário" um poder que deve conjugar seu próprio interesse, o do Estado e o da sociedade.

Necessário se faz a interpretação e aplicação dos conceitos e institutos jurídicos que assegure não apenas as liberdades individuais e as igualdades formais, mas que garanta a proteção integral da pessoa humana. 
Em conclusão, a dignidade da pessoa humana constitui um valor que atraia a realização dos direitos fundamentais do homem, em todas as suas dimensões, e, como a democracia é o único regime político capaz de propiciar a efetividade desses direitos, o que significa dignificar 0 homem, é ela que se revela como o seu valor supremo, o valor que a dimensiona e humaniza. (SCHIMITT, 1996)

No entender de Schmitt todos os direitos fundamentais autênticos são direitos fundamentais absolutos. A propriedade teria sido relativizada pela limitação de seu conteúdo em virtude da função social, não podendo ser considerada como um direito fundamental, mas uma garantia constitucional (DERANI, 1997).

Porém, o processo de publicização do Direito, trouxe uma nova concepção aos direitos fundamentais, que não podem mais atender de forma plena as liberdades individuais, senão interligando às liberdades sociais.

\begin{abstract}
Os Direitos Fundamentais exerciam preponderantemente funções limitativas (o exercício da liberdade individual só é limitado pelo exercício da liberdade de outro). Hoje, seu maior papel está em ações constitutivas operadas tanto pelo Estado como pelos agentes privados. Esta compreensão nova e inovadora dos Direitos Fundamentais está pautada numa premissa essencial que é a de que liberdades individuais são indissociáveis das liberdades sociais ou coletivas. A realização do indivíduo não é passível de ser alcançada sem a concreta difusão das liberdades pela sociedade como um todo $(\mathrm{KICH}, 2004)$.
\end{abstract}

Para a noção de propriedade com justa distribuição de benefícios e encargos garantindo uma cooperação social, Kich (2004) diz que o proprietário da terra que não the der ocupação para produção e destino econômico, estará com sua conduta deixando de produzir bens necessários ao abastecimento da comunidade.

A disponibilidade total sobre o bem, ou sua acumulação para estoque de algumas pessoas, esbarra na necessidade do uso das coisas em favor dos membros da comunidade. 
Ademais, sendo garantido o direito de uso e fruição da coisa através da proteção da propriedade, e havendo inércia por parte do seu titular, deixa de ser lógico garantir propriedade a quem a abandonou, enquanto outros a necessitam para subsistência.

\section{CONSIDERAÇÕES FINAIS}

Este estudo procurou reunir as principais teorias a respeito da origem e fundamentação da propriedade. Analisando as idéias dos autores jusnaturalistas: Locke, Rousseau e Hobbes constata-se a característica atribuída à propriedade, como pressuposto da liberdade individual.

Nesta fase da modernidade, orientada pelo liberalismo, vislumbra-se a propriedade como fim, isto é, como riqueza para acumulação e não como um meio para subsistência humana. Com a transformação do Estado Liberal em Estado Democrático, há uma prevalência do ideário social e uma preocupação com a função social da propriedade.

Em cumprimento à função social, a propriedade deve ser útil não somente ao seu proprietário, mas deve servir ao interesse social. Pois considerar a propriedade absoluta e admitir tamanha liberdade resultaria em impedir o direito dos outros membros da comunidade.

Destarte, ao mesmo tempo em que a Constituição assegura a propriedade como direito fundamental, limita seu exercício ao cumprimento de uma função social, resultando num questionamento acerca do seu caráter de direito fundamental. Haja vista muitos autores conceberem os direitos fundamentais como direitos absolutos.

De outro vértice, podemos entender a propriedade em analogia à soberania dos Estados Contemporâneos, é absoluta desde que não exista desconformidade com os direitos alheios. Assim, propõe-se pensar os direitos fundamentais numa ótica de liberdades sociais e não apenas individuais.

\section{REFERÊNCIAS}


BOBBIO, Norberto. Dicionário de Política. Brasília: UNB, 1994.

BONAVIDES, Paulo. Curso de direito constitucional. 8. ed. rev. atual. e ampl. São Paulo: Malheiros, 1999.

CANOTILHO, José Joaquim Gomes. Direito Constitucional. 6. ed. rev. Coimbra: Livraria, 1995.

CHAMOUN, Ebert. Instituições de Direito Romano. 3. ed. Rio de Janeiro: Forense, 1957.

COSTA, Cássia Celina Paulo Moreira da. A Constitucionalização do Direito de Propriedade Privada. Rio de Janeiro: América Jurídica, 2003.

DERANI, Cristiane. Direito Ambiental Econômico. São Paulo: Max Limonad, 1997.

FRANZONI, Denise Paulus de Campos. Público e Privado: Divisão, Dicotomia e realidade. OLIVEIRA, Álvaro Borges de \& PASOLD, César Luiz. Teoria Jurídica das Relações Interpessoais. Florianópolis: Momento Atual, 2004.

FUSTEL DE COULANGES. A cidade Antiga. São Paulo: Edameris, 1966, v.1.

HOBBES, Thomas. Leviatã ou matéria, forma e poder de um Estado eclesiástico e civil. Coleção Os pensadores. São Paulo: Abril Cultural, 1983.

$\mathrm{KICH}$, Bruno Canísio. A propriedade na ordem jurídica econômica e ideológica. Porto Alegre: Sergio Antonio Fabris Editor, 2004.

LOCKE, John. Segundo Tratado sobre o Governo. Trad. Alex Martins. São Paulo: Editora Martin Claret, 2002.

LOUREIRO, Francisco Eduardo. A propriedade como relação jurídica complexa. Rio de Janeiro: Renovar, 2003.

SERPA LOPES, Miguel Maria. Curso de Direito Civil. v. VI. Rio de Janeiro: Freitas Bastos, 1960.

SILVA, José Afonso da. A dignidade da pessoa humana como valor supremo da democracia. Revista de Direito Administrativo, vol. 212, abr/jun, 1998.

SCHMITT, Carl. Teoria de la Constitución. Madrid: Alianza Editorial, 1996.

WALD, Arnold. Novas Dimensões do Direito de Propriedade. São Paulo: Revista dos Tribunais, 1991, v.665, ano 80. 
WOLKMER, Antônio Carlos. Idéias e Instituições na Modernidade Jurídica. Porto Alegre: SAFE, 1993.

Recebido para publicação: 06/05/2012

Aceito para publicação: 09/08/2012 